\title{
ANÁLISE DE MERCADO DA LIMA ÁCIDA TAHITI
}

TAHITI ACID LIME MARKET ANALYSIS

\author{
Pedro Luis Rossi - pedrorossi089@gmail.com \\ Marcos Alberto Claudio Pandolfi - marcos.pandolfi@ fatectq.edu.br \\ Faculdade de Tecnologia de Taquaritinga (FATEC) -SP -Brasil \\ DOI: 10.31510/infa.v16i2.647
}

\section{RESUMO}

O presente artigo visa apresentar uma análise de mercado para comercialização de uma variedade de citros denominada de lima ácida tahiti. A lima acida tahiti têm grande importância econômica, por isso, o macro segmento no qual essa variedade de fruta está inserida, está alicerçada sobre outras variedades com expressividade econômica também de grande importância, como por exemplo, a laranja doce. Quanto a que se refere a lima ácida tahiti, podemos destacar algumas particularidades de relações comerciais que ao decorrer do trabalho serão apresentadas e percebidas pelo leitor. O objetivo desse trabalho é realizar uma análise de mercado para a fruta citada, consequentemente visualizar se o mercado da mesma está em crescimento ou não.

Palavras-chave: Lima ácida; Citros; Análise de mercado.

\begin{abstract}
This article aims to present develop a market analysis for the commercialization of a variety of citrus called tahiti acid lime. Acid tahiti lime has great economic importance, so the macro segment in which this variety of fruit is inserted, is based on other varieties of great economic importance, such as sweet orange. Regarding the tahiti acid lime, we can highlight some particularities of commercial relations that will be presented and perceived by the reader during the course of the work. The objective of this work is to perform a market analysis for the aforementioned fruit, consequently to see if the market is growing or not.
\end{abstract}

Keywords: Acid Lime; Citrus; Market Analysis

\section{INTRODUÇÃO}

A grande maioria dos frutos cítricos como os limões, limas e laranjas provêm da Ásia. O limoeiro, no início, era um simples arbusto que se espalhava espontaneamente nos campos 
compreendidos entre Índia e o sudeste do Himalaia. Lá ainda é possível encontrar variedades silvestres e primitivas do limão.

Segundo site da empresa ITACITROS, existem diferentes versões sobre a forma como o limão tornou-se conhecido na Europa. Alguns dizem que foi trazido pelos mulçumanos entre os séculos VII e IX, durante o período em que ocuparam grande parte do continente europeu, quando então a difusão desta fruta passou a ser muito rápida.

No entanto, existem relatos de que os romanos já conheciam o limão, usando-o como medicamento, mesmo antes deste fruto ser trazido pelos árabes. De qualquer forma, nas Américas, o limão chegou junto com os primeiros conquistadores portugueses e espanhóis, no século XVI.

Hoje, o Brasil é um dos mais importantes produtores mundiais, especialmente do Limão Tahiti, uma variedade híbrida, resultante do cruzamento do limão Siciliano com a Lima-da-Pérsia, recebendo também o nome, principalmente na Europa, de Lima Ácida ou Lima Ácida Tahiti. A origem do Limão Tahiti no mundo não é claramente conhecida, mas no Brasil é plausível que tenha sido introduzido diretamente do Mediterrâneo a partir do século XVII. A figura 1 ilustra a fruta.

O mercado de frutas torna-se cada dia mais competitivo, deixando assim toda cadeia mais atenta e sempre buscando inovações. O consumo de frutas está em evidencia, claro, frutas de qualidade e que tenha a base agricultável em normas e legislações que visam uma responsabilidade sustentável.

O limão (Citrus latifonia (Yu. Tanaka) Tanaka) é p $7^{\circ}$ produto mais comercializado no CEAGESP. No ano de 2017 foram comercializadas 114.439,62 toneladas de limão. As variedades mais comercializadas no Entreposto Terminal de São Paulo da CEAGESP são: Tahiti (96\%), Estrangeiro Siciliano (2\%), Siciliano (1\%), Rosa (0,7\%), e Galego (0,04\%). As cidades que mais enviam limão tahiti para o Entreposto Terminal de São Paulo são: Itajobi SP $(21,3 \%)$ e Paranapuã - SP (16,7\%), revela pesquisa realizada no site do CEAGESP.

Neste artigo, busca-se analisar o mercado da fruta em questão, obtendo informações que explanam a importância dessa fruta para o país e também para o mundo. O suco do limão Tahiti "in natura" é usado em culinária, na limpeza e preparo de alimentos (carnes, massas, bolos, confeitos). Componente básico da brasileiríssima caipirinha, o limão tahiti é um fruto tropical de ampla utilização. 
Além do uso na culinária e preparo de bebidas, o limão tahiti é utilizado na produção de suco concentrado. Segundo dados do SEBRAE (2016) A indústria de suco utiliza $40 \%$ a $50 \%$ do fruto, sendo o restante considerado resíduo industrial. Esse resíduo contém pectina, vitamina $\mathrm{C}$ e fibras, que os tornam matéria-prima para as indústrias alimentícia, farmacêutica e de rações. O óleo essencial da casca é produto altamente valorizado, com uso amplo na indústria farmacêutica e de refrigerantes.

O presente artigo tem como principal objetivo analisar o mercado do limão Tahiti, a sua evolução durante os anos, destacando seu crescimento no Brasil.

\section{FUNDAMENTAÇÃO TEÓRICA}

O referencial teórico terá como base as principais histórias sobre o surgimento da fruta, tanto como sua evolução com o passar dos anos, até o cenário atual, quais padrões são exigidos para sua denominação e suas principais características. No referencial teórico é onde se discutem os diferentes pontos de vista de autores diferentes sobre o mesmo assunto. Ele se consiste em expor as ideias e com o intuito de fazer com que os leigos absorvam o máximo de conteúdo possível. (LOPES, 2006).

Com uma rentabilidade que em muitos casos pode superar a da laranja, cujos pomares foram assolados pelo avanço de doenças como o greening, o limão Tahiti tem atraído a atenção de pequenos e médios citricultores do interior de São Paulo, segundo a agência paulista de promoção de Investimentos e Competitividade, ainda que a demanda nos grandes centros consumidores do país esteja firme, na mira dos produtores está o aumento da demanda em países que, até pouco tempo atrás, recorriam ao verde de sua casca sobretudo para decorar drinques e prato. (Revista Investe SP, 2016)

Figura 1. Lima Ácida Tahiti 


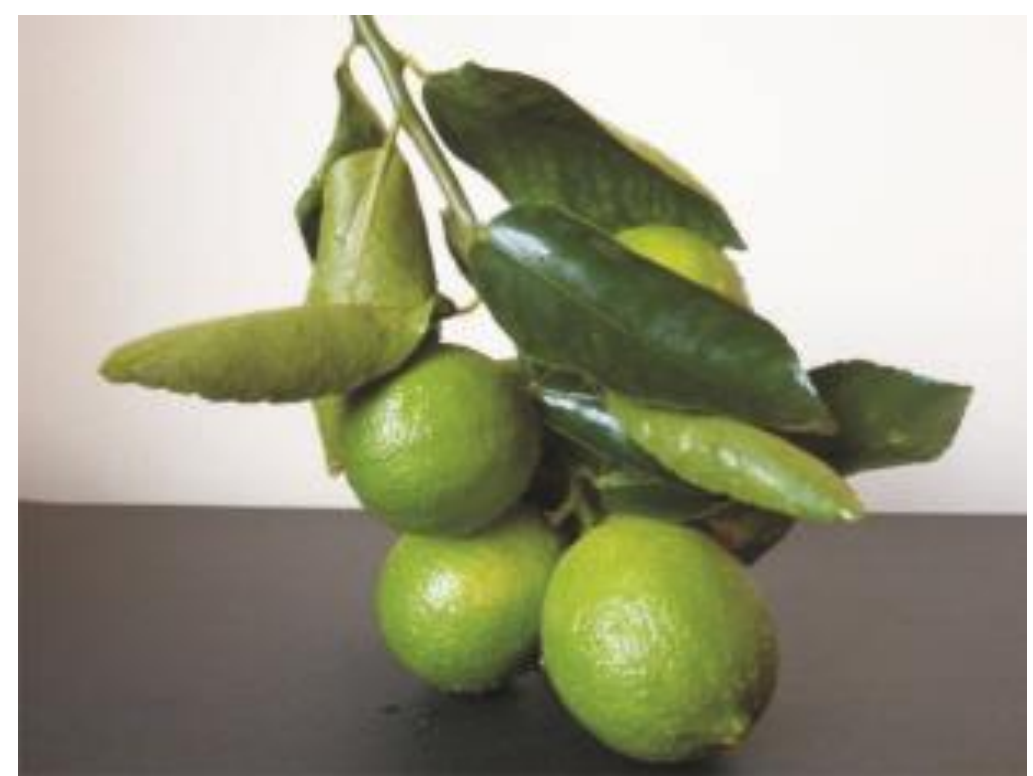

Fonte: EMBRAPA (2012)

Com o consumo inicialmente concentrado na América do Sul e no Caribe, onde as condições de cultivo também são apropriadas, a espécie passou a conquistar novas fronteiras principalmente na última década.

Só para a União Europeia, principal destino das exportações brasileiras, o volume de embarques alcançou 80,8 mil toneladas em 2015, $91 \%$ a mais que em 2005, segundo dados do Ministério da Agricultura.

No total, as exportações brasileiras de limão Tahiti aumentaram 118\% na comparação, para 96,6 mil toneladas. Com a disparada, a produção paulista, que responde por $70 \%$ do total nacional, passou a oscilar de 30 milhões a 44 milhões de caixas de 22 quilos por safra, de acordo com cálculos do Instituto de Economia Agrícola (IEA) da Secretaria da Agricultura do Estado.

A figura 2 apresenta a evolução das exportações da lima ácida Tahiti. (CITRUSBR, 2016)

Figura 2 - Exportações Brasileiras de Limão 


\section{Novo patamar}

Exportaçõ̉es brasileiras de limão*

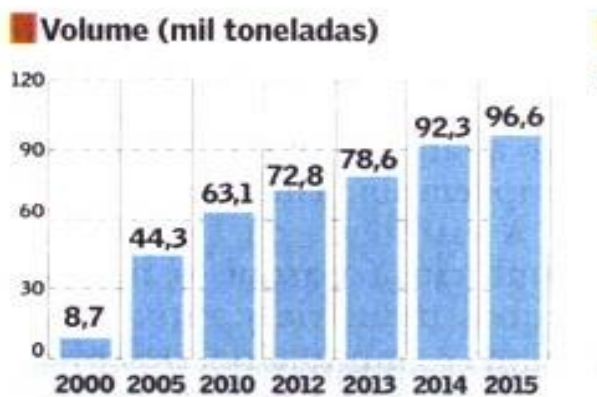

IlValor (US\$ milhōes)

120

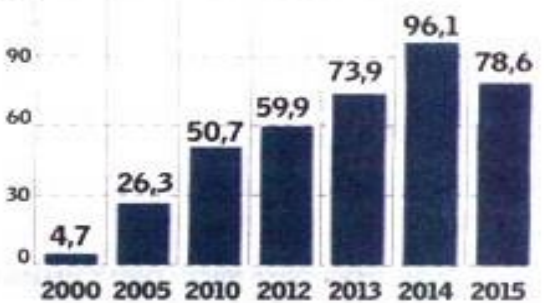

Limão x laranja - Preços médios em SP (R\$/caixa)

Limão tahiti (caixa de $27 \mathrm{~kg}$ )

Laranja (caixa de $40,8 \mathrm{~kg}$ )

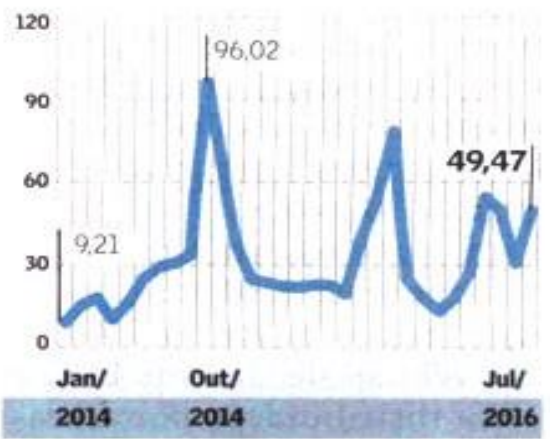

20

17,59

17

14
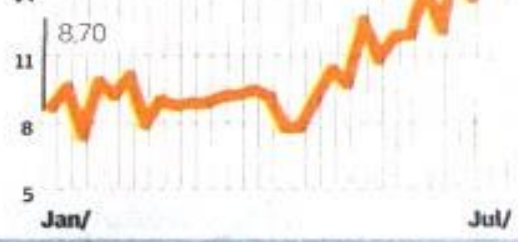

2014

2016

Fontes: Ministerio da Agricultura e IEA. - Incluindo todas as variedades

Fonte: IEA (2016)

\section{PROCEDIMENTOS METODOLÓGICOS}

Para a elaboração do artigo foi realizada pesquisa bibliográfica, a partir do levantamento de referências teóricas já analisadas, e publicadas por meios escritos e eletrônicos, como livros, artigos científicos e websites.

Segundo Gil (2007, p. 44), os exemplos mais característicos desse tipo de pesquisa são sobre investigações e ideologias ou aquelas que se propõem à análise das diversas posições acerca de um problema.

\section{RESULTADOS}

Atualmente, o Brasil é o principal exportador de limão "tahiti" para o mercado europeu, tendo como destino final os países baixos que absorveu a maior parte do limão "in natura”, diferentemente do México, no qual, seu principal importador é os Estados Unidos, mas, em determinadas oscilações de mercado, interferem no principal cliente brasileiro. No 


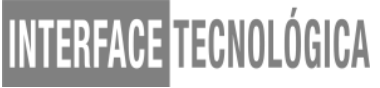

cenário mundial, vários países com aptidão citrícola estão investindo na produção do limão "Tahiti" e visando consequentemente o mercado internacional, assim, aumentando a concorrência com os produtores brasileiros.

Conforme gráfico elaborado pelo ministério da indústria, comercio exterior e serviços, no ano de 2017 em relação à 2016 houve um decréscimo nas exportações de lima ácida Tahiti, conforme apresentado na figura 3.

Figura 3 - Valor exportado (USS) - Limões e limas, frescos ou secos

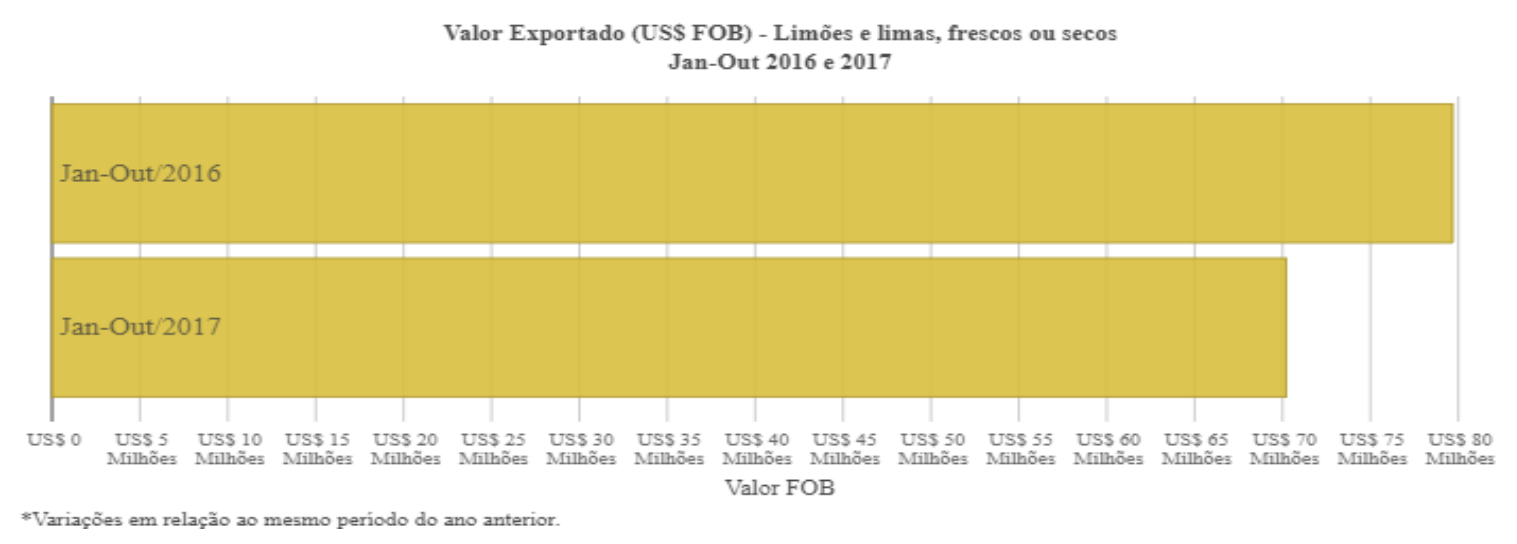

Fonte: IEA (2017)

A figura 3 apresenta dois tipos identificados de dados, primeiramente que o valor das exportações recebidas pela fruta foi menor em comparação ao ano anterior, outro dado que foi exposto foi que o volume exportado também caiu, decorrência de menor consumo europeu da lima ácida Tahiti. Fato curioso que deve ser explanado é que as exportações Mexicanas da mesma fruta subiram para Europa, onde não é seu maior mercado consumidor e sim os EUA. Então devemos fazer uma analise critica sobre esses dados, primeiramente é sobre preferência do limão mexicano para o consumo em relação ao do Brasil, isso é extremamente evidenciado já que sua qualidade de casca é superior, segundo é que as exportações mexicanas para os EUA recebiam menos em relação exportada à Europa.

Segundo a revista Dinheiro Rural, em pesquisa realizada com produtores e colaboradores do Cepea, no mercado internacional, a valorização pode chegar a $25 \%$ comparado com os preços do mercado interno. Pela cotação do Centro de Estudos Avançados em Economia Aplicada (Cepea/Esalq), de Piracicaba (SP), a caixa de 27,2 quilos, que é o padrão de medição da fruta no atacado, chegou a $\mathrm{R} \$ 33,00$ no exterior, no ano passado.

No País, essa mesma caixa era vendida a $\mathrm{R} \$ 26,60$. Já na comparação entre os preços do limão e da laranja do mercado interno, em 2015, enquanto o quilo do limão ficou numa 
média de $\mathrm{R} \$ 0,98$, o da laranja era 2,6 vezes menor, ou $\mathrm{R} \$ 0,37$. O Brasil colhe atualmente, 1,1 milhão de toneladas de limão, das quais $91 \%$ ficam no mercado interno e $9 \%$ são exportadas. É justamente a fruta para exportação, por causa da moeda americana valorizada, que tem atraído os produtores, relata Fernanda, analista econômica do Cepea.

De acordo com a analista econômica do mercado de citros do Cepea/Esalq, Fernanda Geraldini Palmieri, o cenário para o limão é, de fato, promissor porque o Brasil tem se tornado cada vez mais referência e um grande fornecedor confiável da fruta. "O limão ganhou mercado mesmo foi na Europa, hoje o principal comprador", diz Fernanda. "Por lá, ele é considerado uma fruta exótica, ganhando espaço na culinária e na preparação de bebidas." No ano passado, os europeus, especialmente a Holanda e o Reino Unido, compraram 81 mil toneladas, ou $84 \%$ do total exportado. Porém, para a indústria exportadora, o grande salto seria alcançar o mercado americano.

Os Estados Unidos, país no qual o Brasil ainda não tem acesso, pois o limão produzido no país não consegue atravessar as barreiras legislativas como também as fitossanitárias, impostas pelo país, que temem a mosca das frutas, impedindo a importação de diversas frutas, porém os Estados Unidos importam 400 mil toneladas anuais da fruta, que têm o México como principal vendedor, figurando como o maior comprador mundial.

A figura 4 apresenta uma evolução de preços praticados para a lima ácida Tahiti e Laranja.

Figura 4 - Escalada de preços (Mercado interno - Atacado)- Limão e Laranja

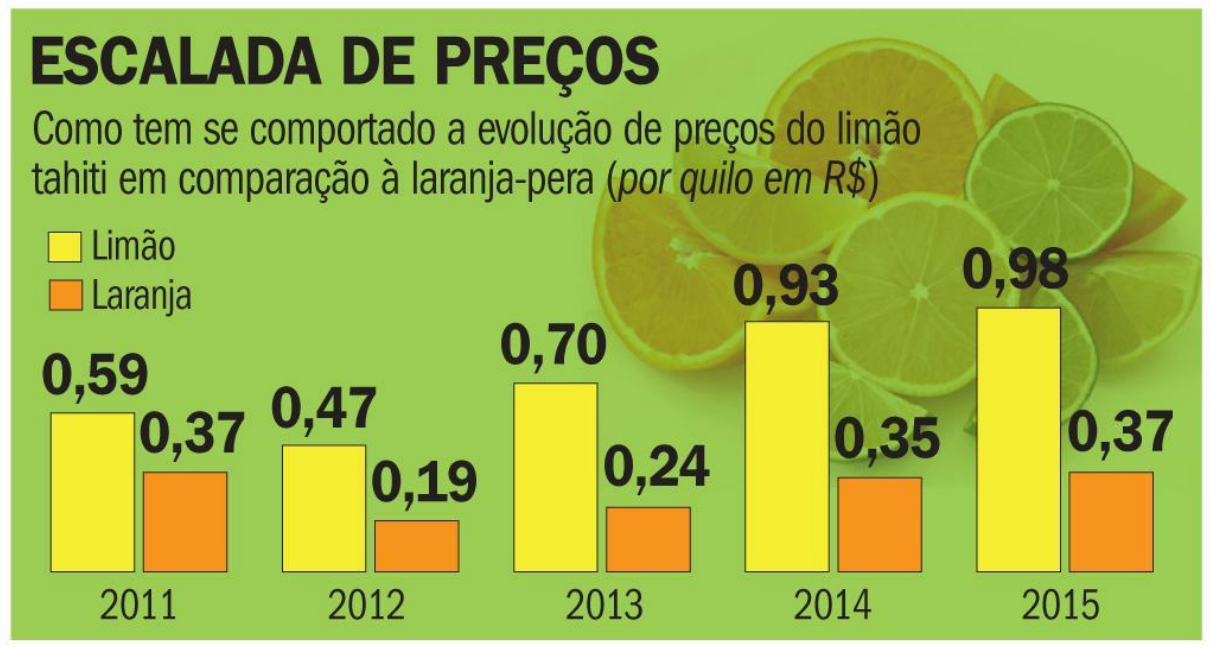

Fonte: Cepea/Esalq

Fonte: Cepea/Esalq (2015) 
Analisando a figura 4, é possível notar que, enquanto os preços da laranja permaneceram estáveis entre 2011 e 2015, o preço da lima ácida apresentou um incremento de $66,1 \%$, demonstrando o potencial de crescimento muito interessante.

\section{CONSIDERAÇÕES FINAIS}

Atualmente o mercado do limão está em crescimento, com um país propício para se cultivar essa fruta, cada vez mais a Lima Ácida Tahiti ganha destaque. Pequenos produtores conseguem disponibilizar ao mercado uma fruta com grande qualidade, para que esta possa ser comercializada não só no Brasil, mas também na Europa.

O estudo realizado sobre o limão Tahiti foi devido ao seu grande potencial, podendo ser considerado referência nacional na comercialização. Onde oferecendo grande qualidade de fruto, têm-se a chance de ingressar no mercado consumidor, bem como aproveitando ao máximo a capacidade produtiva da fruta.

Outros países que estão no mercado podem ser considerados como ameaça para o limão brasileiro, portanto, deve-se atuar com a alta qualidade do produto para que ele possa obter a preferência do mercado consumidor. $\mathrm{O}$ foco para um empreendimento de limão Tahiti é o beneficiamento do mesmo, fazendo com que a fruta ganhe em estética e também em vitalidade.

Com base nas informações obtidas no presente artigo, percebe-se que o mercado do limão vem crescendo ano após ano, com grande chance de o limão brasileiro entrar também nos Estados Unidos, a esperança é que os produtores brasileiros tenham cada vez mais a ganhar com o cultivar desta fruta.

Cabe ressaltar que a busca contínua por melhoria dos processos de produção, treinamento e capacitação das pessoas envolvidas nas atividades e buscar por novas parcerias e clientes fazem com que a empresa consiga atingir uma ascensão constante no mercado de exportação que está cada vez mais competitivo.

\section{REFERÊNCIAS}

BREMER NETO, H. et al. Caracterização tecnológica e aptidão mercadológica de clones de lima ácida "Tahiti". Acesso em: 15 de Ago 2019. 
CEAGESP. Limão Tahiti. 2019. Disponível em: <http://www.ceagesp.gov.br/guiaceagesp/limao/> Acesso em: 07 de Nov de 2019.

CEPEA. Citros: Tahiti valoriza 20\%. 2016. Disponível em: < https://www.cepea.esalq.usp.br/br/diarias-de-mercado/citros-tahiti-valoriza-20.aspx> Acesso em 13 de Ago 2019.

CITRUSBR. Limão Tahiti conquista mercados e produtores. 2016. Disponível em: < http://www.citrusbr.com/noticias/?id=312256> Acesso em: 14 de Ago de 2019.

CONGRESSO BRASILEIRO DE FRUTICULTURA. Anais... Frutas: saúde, inovação e responsabilidade. Natal: Sociedade Brasileira de Fruticultura, 2010. Disponível em: \&lt;https://www.alice.cnptia.embrapa.br/handle/doc/873309\&gt; Acesso em: 16 de Ago 2019.

GAYET, J. P.; SALVO FILHO, A. Colheita e beneficiamento. In: MATTOS JUNIOR, D. de DE. Acesso em: 15 de Ago 2019.

GIL, A.C. Métodos e técnicas de pesquisa social. São Paulo: Atlas, 2007. Acesso em: 11 de Ago 2019.

INVESTE SÃO PAULO. Limão tahiti conquista mercados e produtores. 2016. Disponível em: < https://www.investe.sp.gov.br/noticia/limao-tahiti-conquista-mercados-e-produtores/> Acesso em: 14 de Ago 2019.

ITACITROS. A origem do limão tahiti. 2010. Disponível em: <http://itacitrus.com/international/pt/Tahiti.aspx> Acesso em: 14 de Ago de 2019.

NACHREINER, Maria Luiza. DOS SANTOS, Renata Romaguera Pereira. Janelas de mercado: a fruticultura brasileira no mercado internacional. 2003. Disponível em: $<$ https://www.cepea.esalq.usp.br/br/documentos/texto/janelas-de-mercado-a-fruticulturabrasileira-no-mercado-internacional-ago-2003-xli-sober.aspx> Acesso em: 03 de Set 2019.

NEGRI, J.D. FIGUEIREDO, J.O. Campinas: Instituto Agronômico, 2003. p. 147- 162. Acesso em: 12 de Ago 2019.

NEVES, M. F. et al. O retrato da citricultura brasileira. p. 138, 2010. Acesso em: 18 de Ago 2019.

REVISTA DINHEIRO RURAL. O doce negócio do limão. 2016. Disponível em: < https://www.dinheirorural.com.br/secao/agronegocios/o-doce-negocio-do-limao> Acesso em: 17 de Ago 2019.

SEBRAE. O cultivo e o mercado do limão. 2016. Disponível em: < http://www.sebrae.com.br/sites/PortalSebrae/artigos/o-cultivo-e-o-mercado-dolimao,9e7a9e665b182410VgnVCM100000b272010aRCRD> Acesso em: 13 de Ago 2019.

SPÓSITO, M. B. E. et al. Armazenamento refrigerado de frutos de limeira-ácida "Tahiti" tratados com GA. Revista Brasileira de Fruticultura,v. 22, n. 3, p. 345-348, 2000. Acesso em: 20 de Ago 2019. 